\title{
ESTUDO COMPARATIVO DA PASSIVAÇÃO DO AÇO AISI 316-L COM ÁCIDO NÍTRICO E ÁCIDO SULFÚRICO EM DIFERENTES TEMPERATURAS.
}

\author{
V.V. FREITAS ${ }^{1}$, K. J. B. ALVES ${ }^{1}$, M. F. ROMEU ${ }^{1}$ e M. M. P. SILVA ${ }^{1,2}$ \\ ${ }^{1}$ Faculdade de São Bernardo do Campo, Departamento de Química \\ ${ }^{2}$ Faculdade de São Bernardo do Campo, Departamento de Engenharia Química \\ E-mail para contato: mauricio.marques@fasb.com.br
}

\begin{abstract}
RESUMO - Este estudo teve por objetivo propor métodos de proteção passivante a aços inoxidáveis, de forma a aumentar sua resistência à corrosão, tendo em vista a vasta utilização no cotidiano como, por exemplo, em equipamentos expostos à atmosfera. Foram comparados os limites de passivação para aço austenítico de baixo teor de carbono (AISI 316-L), utilizando-se banhos passivantes de ácido nítrico e ácido sulfúrico, com os quais se verificou se a influência da temperatura dos banhos pode ser significativa para uma melhor proteção passiva ao aço. As placas de aço AISI 316-L passaram por decapagem mecânica, posteriormente lavadas com água destilada e secadas com ar quente na temperatura de $55^{\circ} \mathrm{C}$; em seguida, foram imersas em solução de $\mathrm{HNO}_{3} 40 \%$ v/v ou solução de $\mathrm{H}_{2} \mathrm{SO}_{4} 0,50$ mol. $\mathrm{L}^{-1} 15 \%$, em temperaturas ambiente $\left(20^{\circ} \mathrm{C}\right)$ e $40^{\circ} \mathrm{C}$, formando-se assim uma camada passiva sobre a superfície do aço. As placas foram expostas a meios corrosivos de $\mathrm{HCl}$, acompanhando-se os valores de Eca (potencial de circuito aberto) até valores estacionários (potencial de corrosão - Ecorr). Com os dados obtidos, verificou-se a eficácia em todas as condições propostas; entretanto, a passivação com $\mathrm{HNO}_{3} 40 \%$ v/v em temperatura de $40^{\circ} \mathrm{C}$, apresentou uma melhor performance.
\end{abstract}

\section{INTRODUÇÃO}

Corrosão é o processo de deterioração espontânea de um metal, causada pela reação entre o metal e os elementos do meio em que o mesmo está imerso. Com o crescente uso de aços, como os aços inoxidáveis utilizados em materiais cirúrgicos, cresce também a importância dos estudos sobre os processos que inibem a ação do processo corrosivo na superfície metálica (GENTIL, 2007).

Os aços inoxidáveis apresentam grande resistência à corrosão devido à quantidade de cromo presente em sua composição. Sendo assim, o cromo, um dos constituintes do aço austenítico, sofre oxidação, resultando em uma fina camada de óxido de cromo na superfície do metal, a qual o protege do ataque corrosivo. A esse processo de formação da camada de óxido sobre a superfície do metal dá-se o nome de passivação (GEMELLI, 2001).

De acordo com a norma técnica ASTM - A967 / A967M-13, existe uma forma de passivação a ser aplicada para cada tipo de aço, sendo que o processo de passivação abrange 
diversas variáveis como o tempo de imersão, a temperatura e a concentração do banho passivante.

Segundo Salvago et al (1987), o pré-tratamento com $\mathrm{HNO}_{3}$ em ensaios de laboratório, pode impedir a corrosão em placas de aço AISI 316, quando expostas a meios clorados. Isto posto, e com estudos anteriores de comparativos dos limites de passivação com aços de mesma classe, proporcionaram o anseio para a elaboração deste trabalho.

Como proposto por Jesus et al (2015), os limites de passivação para o aço AISI 316-L aumentam quando passivados com $\mathrm{HNO}_{3} 40 \%$ (v/v), e com o aumento de temperatura geram uma camada mais compacta, elevando ainda mais este limite. Conforme Alves et al (2016), para o aço AISI 316-L, a passivação com $\mathrm{H}_{2} \mathrm{SO}_{4} 0,5$ mol.L ${ }^{-1} 15 \%$ em temperatura ambiente $\left(20^{\circ} \mathrm{C}\right)$ é eficaz, sendo comprovada a formação de camada passivada, proporcionando um maior limite de passivação.

\section{MATERIAIS E MÉTODOS}

Duas placas de aço AISI 316-L inicialmente passaram por decapagem mecânica utilizando-se lixas de granulometria 320, 400 e 600 mesh, sucessivamente, com o intuito de retirar impurezas e minimizar as imperfeições das placas. Em seguida, as placas foram lavadas com jatos de água destilada para retirar vestígios de partículas em contato, posteriormente realizando-se a secagem com ar quente, na temperatura de $55^{\circ} \mathrm{C}$. Com as placas devidamente preparadas, foram imersas em solução de ácido nítrico $40 \%$ (v/v) ou solução de ácido sulfúrico 0,50 mol. $\mathrm{L}^{-1}$ a $15 \%$, para proporcionar a formação de uma camada passiva protetora, tendo como variável a temperatura ambiente $\left(20^{\circ} \mathrm{C}\right)$ e a $40^{\circ} \mathrm{C}$, ambas por tempo determinado de 30 minutos. Decorrido o tempo de imersão, as placas foram retiradas do banho passivante, sendo lavadas novamente com água destilada, e secada com ar quente, novamente a $55^{\circ} \mathrm{C}$. Para avaliação da resistência à corrosão, as placas passivadas foram submetidas a meios corrosivos de ácido clorídrico em diferentes concentrações, e com auxílio de multímetro e de eletrodo de calomelano saturado como referência, acompanharam-se os valores dos potenciais de circuito aberto (Eca) por 60 minutos, tempo necessário para estabilização e obtenção de potenciais quase-estacionários (potenciais de corrosão - Ecorr). 


\section{RESULTADOS E DISCUSSÕES}

Tabela 1 - Valores de potencial de corrosão (mV/ECS) para o aço AISI 316-L em meio corrosivo de $\mathrm{HCl}$, com meios passivantes de $\mathrm{HNO}_{3} 40 \%$ (v/v) e $\mathrm{H}_{2} \mathrm{SO}_{4}$ 0,50 mol.L $\mathrm{L}^{-1}$ (15\%)

\begin{tabular}{|c|c|c|c|c|c|c|}
\hline \multicolumn{7}{|c|}{ AISI 316-L } \\
\hline \multirow{2}{*}{\multicolumn{2}{|c|}{$\begin{array}{c}\text { Meio } \\
\text { Corrosivo }\end{array}$}} & \multirow{2}{*}{$\begin{array}{c}\text { Sem } \\
\text { Passivação }\end{array}$} & \multicolumn{2}{|c|}{$\mathrm{HNO}_{3} 40 \%(\mathrm{v} / \mathrm{v})$} & \multicolumn{2}{|c|}{$\begin{array}{c}\mathrm{H}_{2} \mathrm{SO}_{4} 0,50 \text { mol. } \mathrm{L}^{-1} \\
(15 \%)\end{array}$} \\
\hline & & & Ambiente & $40^{\circ} \mathrm{C}$ & Ambiente & $40^{\circ} \mathrm{C}$ \\
\hline \multirow{6}{*}{$\begin{array}{c}\mathrm{HCl} \\
\left(\mathrm{mol}^{-1} \mathrm{~L}^{-1}\right)\end{array}$} & 0,10 & $-169 \pm 4$ & $-77 \pm 1$ & $-20 \pm 8$ & $-85 \pm 1$ & $-72 \pm 5$ \\
\hline & 0,30 & $-146 \pm 2$ & $-80 \pm 6$ & N/A & $-110 \pm 1$ & $-76 \pm 5$ \\
\hline & 0,50 & $-355 \pm 2$ & $-119 \pm 1$ & $-50 \pm 11$ & $-115 \pm 2$ & $-49 \pm 5$ \\
\hline & 0,70 & $-358 \pm 2$ & $-85 \pm 1$ & $-72 \pm 5$ & $-150 \pm 1$ & $-93 \pm 1$ \\
\hline & 0,90 & $-362 \pm 2$ & $-366 \pm 2$ & $-49 \pm 40$ & $-369 \pm 1$ & $-366 \pm 1$ \\
\hline & 1,00 & $-330,0 \pm 0,5$ & - & $-376 \pm 17$ & - & - \\
\hline
\end{tabular}

Conforme a tabela 1, observam-se os resultados de comparação da passivação do aço AISI 316-L em meios de ácido nítrico $40 \%$ (v/v) e ácido sulfúrico 0,50 mol.L ${ }^{-1}$, em temperatura ambiente $\left(20^{\circ} \mathrm{C}\right)$ e $40^{\circ} \mathrm{C}$, e sem passivação.

Quando é realizada a passivação do aço AISI 316-L, em meios de ácido nítrico 40\% (v/v) e ácido sulfúrico $0,50 \mathrm{~mol} \cdot \mathrm{L}^{-1}(15 \%)$, há a formação de uma camada passiva que promove uma maior resistência ao aço quando exposto ao meio corrosivo de $\mathrm{HCl}$, fato evidenciado pelos valores de potenciais mais catódicos de Ecorr, em relação aos aços não passivados. 
Figura 1 - Potenciais de circuito aberto (mV/ECS) para as passivações de $\mathrm{HNO}_{3} 40 \%$ (v/v) e $\mathrm{H}_{2} \mathrm{SO}_{4}$ 0,50 mol.L ${ }^{-1}$ (15\%), realizados com aço AISI 316-L, em meio corrosivo de $\mathrm{HCl} 0,90$ mol. $L^{-1}$

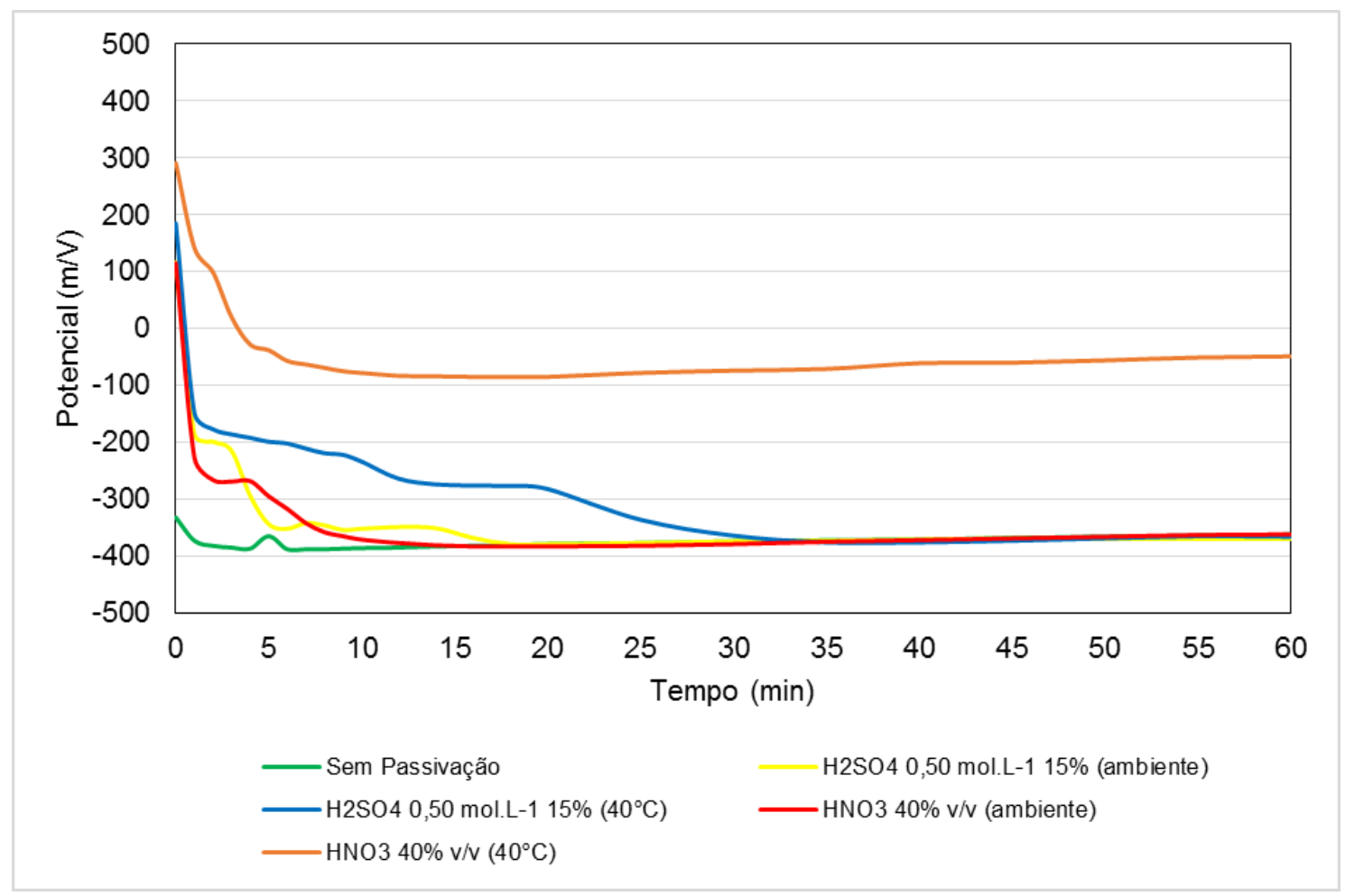

$\mathrm{O}$ aço 316-L quando submetido a temperaturas mais elevadas, apresenta comportamento semelhante com a temperatura ambiente em relação à resistência, quando exposto aos meios corrosivos de $\mathrm{HCl}$, como se pode observar na figura 1. Com a passivação com ácido nítrico $40 \%(\mathrm{v} / \mathrm{v})$ em temperatura ambiente, resistiu até $\mathrm{HCl} 0,90 \mathrm{~mol} \cdot \mathrm{L}^{-1}$, enquanto que com o mesmo meio passivante, mas com temperatura de $40^{\circ} \mathrm{C}$, resistiu até $\mathrm{HCl} 1,0$ mol.L $\mathrm{L}^{-1}$. A passivação com o ácido sulfúrico 0,50 mol. $\mathrm{L}^{-1}$ (15\%), nas duas condições de temperatura, ambiente e $40^{\circ} \mathrm{C}$. apresentaram a mesma eficiência contra a corrosão, resistindo até $\mathrm{HCl} 0,90$ mol.L $L^{-1}$.

\section{CONCLUSÕES}

Com os dados obtidos neste trabalho, pode-se observar os limites de passivação em temperatura ambiente $\left(20^{\circ} \mathrm{C}\right)$ e $40^{\circ} \mathrm{C}$, para o aço AISI 316-L, com passivação em $\mathrm{H}_{2} \mathrm{SO}_{4} 0,50$ mol.L-15\% e em $\mathrm{HNO}_{3} 40 \%$ (v/v).

A passivação com $\mathrm{HNO}_{3} 40 \%$ (v/v) no aço AISI 316-L, mostrou-se ser mais eficiente com o aumento de temperatura, uma vez que, com temperatura ambiente, houve uma resistência ao meio corrosivo até $\mathrm{HCl}$ 0,90 mol. $\mathrm{L}^{-1}$. Quando o aço foi submetido a uma

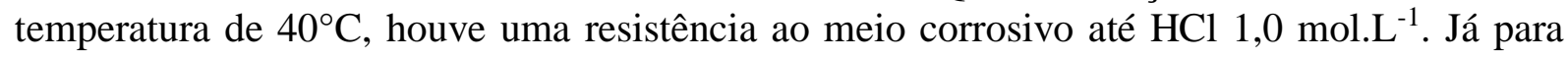
passivação com $\mathrm{H}_{2} \mathrm{SO}_{4} 0,50$ mol.L-1 $15 \%$, pode-se observar uma igualdade em resistência ao meio corrosivo até $\mathrm{HCl}$ 0,90 mol. $\mathrm{L}^{-1}$, assim sendo, o aumento da temperatura não se mostrou ser mais eficiente como no tratamento com $\mathrm{HNO}_{3} 40 \%$ (v/v). Pode assim ser comprovado que 
o tratamento do aço AISI 316L com $\mathrm{HNO}_{3} 40 \%$ (v/v) à temperatura de $40^{\circ} \mathrm{C}$, mostra ser mais eficiente aos meios corrosivos estudados.

A partir dos dados de potenciais de corrosão (Ecorr) mais catódicos em ambas as condições de passivação, foi possível comprovar a formação de camada passiva, que proporciona uma proteção ao aço, nos meios corrosivos de $\mathrm{HCl}$. (FASB).

Agradecimentos: Fundação João Ramalho / Faculdade de São Bernardo do Campo

\section{REFERÊNCIAS}

ALVES, K.J.B.; FREITAS, V.V.; MARQUES, M.M.; SILVA, M.M.P. Estudo comparativo dos limites de passivação dos aços AISI 304-L e AISI 316-L com ácido nítrico e ácido sulfúrico. In: CONGRESSO BRASILEIRO DE QUÍMICA, 56., 2016, Belém.

AMERICAN SOCIETY FOR TESTING AND MATERIALS. A967 / A967M-13: Standard Specification for Chemical Passivation Treatments for Stainless Steel Parts. West Conshohocken, 2007.

GEMELLI, E. Corrosão de materiais metálicos e sua caracterização. $1^{\text {a }}$ ed. Rio de Janeiro: LTC, 2001.

GENTIL, V. Corrosão. $5^{\text {a }}$ ed. Rio de Janeiro: LTC, 2007.

JESUS, F.H.C. et al. Estudo comparativo dos limites de passivação dos aços AISI 304-L e AISI 316-L com ácido nítrico em diferentes temperaturas. In: CONGRESSO BRASILEIRO DE QUÍMICA, 55., 2015, Goiânia.

SALVAGO, G.; FUMAGALLI, G.; MOLLICA, A.; VENTURA, G. A statistical evaluation of AISI 316 stainless steel resistance to crevice corrosion in $3,5 \% \mathrm{NaCl}$ solution and in natural sea water after pre-treatment in $\mathrm{HNO}_{3}$. Corrosion Science, vol. 27, no. 9, pp. 927-936, 1987. 